\title{
TRANSFONDO GENERACIONAL
}

\section{MALLIE COFFEY * Traducción Dr. Julio Flores Konja}

En lo que respecta a lo que es estrictamente la auditoría, los servicios de contabilidad y tributación-lo que las firmas de auditoría también conocen como asesoría financiera-, se ha pasado a nuevas situaciones en un desarrollo del ejercicio profesional y perspectiva laboral. Con la expansión del ejercicio profesional en áreas como los servicios de seguros, asesoría legal, fusiones y adquisiciones de diversos tipos, asistencia a la tercera edad y confiabilidad del sistema, calificación de riesgo, la profesión contable continúa presente en la importante y creciente necesidad de la población, especialmente en la gestión empresarial; salvo un grupo. Sí. la Generación X.

¿Bien, qué hay respecto a la Generación X?, ¿cómo pueden las firmas de auditoría estar al servicio de este único y especial grupo de individuos? y ¿ cómo ellas pueden beneficiarse de la Generación X para con su staff y personal? Para entender cómo la Generación X puede necesitar los servicios de auditoría, debemos aprender un poco sobre la mentalidad de la Generación X.

La Generación X es la generación que surge de las actividades procreativas de los Baby Boomers (persona nacida durante los veinte años después de la Segunda Guerra Mundial; o sea, después del año 1945). Es

(*) Artículo escrito por Mallie Coffey de la Firma Gifford. Hillegass \& Ingwersen. P.C.. miembro de ACPA International Inc., publicado en la revista Update-Actualidad-mes de noviembre. un grupo etiquetado a menudo como holgazanes, vagos, provocadores, quejones, llorones, e incluso matones. Nuestra ética laboral es a menudo malentendida, o en la creencia de ser inexistente. Este problema proviene de la comunicación y de diferentes apariencias que muchas veces son engañosas.

Con respecto a la comunicación, la Generación X es considerada a menudo atrevida, descarada, combativa, e incluso descontenta. Uno puede interesarse en saber lo que se piensa y cree de los Baby Boomers, por intermedio de sus más jóvenes compañeros de ocupación, en lo laborioso del trabajo, en sus sentimientos, su terquedad y aburrimiento. Esto va a demostrar que esa etiqueta negativa y de término, se detracta del objetivo común: el incremento de ventas en servicios y/o producto. La Generación X. en términos de comunicación e información, quiere estar vigente dando valor agregado a todas sus contribuciones. Algunas veces este miembro de la Generación X, querrá cambiar la forma en que se hizo, se presenta o se maneja. Personalmente uno no tiene porque estar de acuerdo, de hecho él o ella probablemente tampoco lo esperan. Pero a la luz de la apertura de las comunicaciones, el incremento de las ventas y de servicios, $y$ si personalmente se da validez a la idea de ellos, debemos reconocer el aporte de la Generación X a la empresa.

En apariencia es un asunto susceptible. Algunas personas creen que la imagen lo es todo. Algunos creen en el adagio de poder juzgar un libro por su tapa. ¿Qué se le puede señalar a la Generación X? Efectivamente, algunos de nosotros tenemos tatuajes, $y$ quizás un cuerpo con un agujero o dos. Y claro, la conducta tiene que ser trazada de modo que sea apropiada a la imagen comercial. Desgraciadamente las etiquetas negativas se impusieron, y las medidas extremas se tomaron. La verdad debe ser 
dicha, las concesiones pueden aceptarse. Un individuo de la Generación X gustará parecer profesional. Sólo que nuestra idea de un profesional podría no coincidir con las ideas de un Baby Boomer, por lo que se necesita establecer las normas. Pero no se puede ser demasiado estricto. Si alguien se niega a contratar a personas con tatuajes, podría despediciar algún talento. Yo tengo dos, y dudo que mis compañeros de trabajo logren distinguirlos. Ellos están demasiado ocupados en sus labores, programando sus reuniones comerciales.

Siendo así ¿cómo conciliar nuestro único grupo? Apoyándonos financieramente. Nosotros queremos las mismas cosas que los Baby Boomers anhelaban en sus $20 \mathrm{y}$ 30 años. Lograr una carrera profesional, cuentas bancarias. inversiones, una casa, familia y seguridad. Utilicemos ese nuevo título de asesor financiero y dejemos el término contador. Lo que necesitamos de la práctica contable es asesoría financiera. ¿Dónde colocar nuestro dinero por el que hemos trabajado tanto? ¿Cómo asegurarnos nuestros recursos? ¿Cómo lograr el despegue de nuestra empresa y pequeña compañía? Creer en nosotros primeramente, antes de lograr ser grandes y rentables, y nos afianzaremos como firma. Necesitamos ser calificados y la mejor manera de hacerlo, es ajustarnos a nuestras necesidades y entender lo que realmente queremos.

La Generación X noes realmente difícil de entender. Quizás nosotros parecemos diferentes por fuera, pero queremos las mismas cosas que todos los seres humanos quieren y lo vamos a conseguir; no obstante, ayudaría mucho que entre empresas nos ayudáramos. 